\title{
CYTOMORPHOLOGY AND CORRELATION WITH THE HISTOPATHO- LOGICAL DIAGNOSIS OF SALIVARY GLAND NEOPLASMS
}

\section{Gouthami S ${ }^{1}$, Sunitha Gattigorla *2, Sheshagiri $T^{3}$.}

${ }^{1}$ Assistant professor in department of pathology, Dr. Patnam Mahendar Reddy Institute of Medical Sciences, Chevella, Telangana, India.

${ }^{* 2}$ Assistant professor in department of pathology, Kamineni Institute of Medical Sciences, Narketpally, Telangana, India.

${ }^{3}$ Professor and Head in department of pathology, Kamineni Institute of Medical Sciences, Narketpally, Telangana, India.

\section{ABSTRACT}

Introduction: FNAC is a highly reliable technique for pre-operative diagnosis of salivary gland tumors in the hands of experienced pathologists. The purpose of this study is to evaluate and to check the diagnostic accuracy and sensitivity and specificity of fine needle aspiration cytology in the diagnosis of salivary gland lesions.

Materials and Methods: In the present study, 85 cases of salivary gland lesions are aspirated in the department of Pathology, of which 60 cases with neoplasms of salivary glands underwent surgery and are included in the study at kamineni institute of medical sciences, Narketpally from October 2015 to September 2017.

Results: The lesions were more common on the Right side (66.66\%), Benign lesions (83.33\%), The lesions were more common in Parotid gland (73.33\%), The Benign neoplasms were 53 cases (88.33\%) of all tumors. Among the Benign neoplasms there were 38 cases of Pleomorphic adenoma, 2 cases of Benign cystic lesion, 1 case of benign spindle cell lesion, 1 case of salivary lipomatosis. Pleomorphic adenoma is the commonest tumor accounting for $92.98 \%$ of all benign tumors. Statistical analysis revealed sensitivity of $71.4 \%$, specificity of $100 \%$ and Diagnostic accuracy of $96.6 \%$. correlation value is 0.631 and $P$ value is 0.00 which is statistically significant.

Conclusion: the present study reaffirms that FNAC of the salivary glands neoplasms, being a quick, safe, and affordable procedure offers an invaluable and highly accurate initial diagnostic approach for the management of patients.

KEY WORDS: Benign lesions, FNAC, Parotid Gland, Pleomorphic adenoma, Salivary Gland Tumors.

Address for correspondence: Dr. Sunitha Gattigorla, Assistant professor in department of pathology, Kamineni Institute of Medical Sciences, Narketpally, Telangana, India.

E-Mail: gattigorlas@gmail.com.

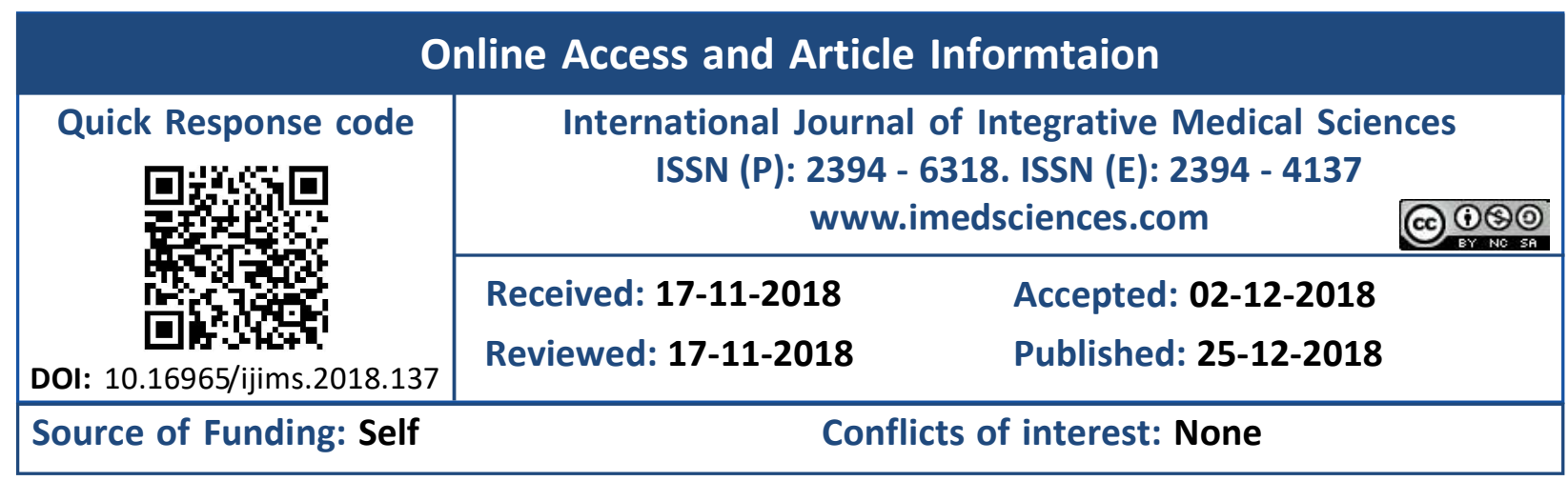

\section{BACKGROUND}

Salivary gland neoplasms comprise a wide variety of both benign and malignant histological subtypes. Salivary gland neoplasms arise from major or minor salivary glands. About $64-80 \%$ of all primary epithelial salivary gland tumors occur in parotid gland, $7-11 \%$ occurs in submandibular salivary glands, less than $1 \%$ occurs in sub lingual salivary glands and $9-23 \%$ occur in minor salivary glands [1]. In the files of armed forces pathology institute (AFIP), about $1 / 3 \mathrm{rd}$. major salivary gland tumors, and half of minor 
salivary gland tumors are malignant. Ratio of malignant to benign tumors is greatest $(>2.3: 1)$ in sub lingual gland, tongue, floor of mouth, retro molar area [2]. Incidence of malignant tumors are more common in women compared to men [3]. Pleomorphic adenoma is the most common benign neoplasm accounting to $52.04 \%$ of tumors, and $80 \%$ of pleomorphic adenomas are seen in the parotid gland. Mucoepidermoid carcinoma is the most common malignant neoplasm, accounting to $4.06 \%$ of tumors and parotid gland is most commonly affected among major salivary glands. Adenoid cystic carcinoma is the second most common malignant neoplasm accounting to $1.63 \%$ of all salivary gland tumors and is seen commonly in the minor salivary glands [4].

Most of the salivary glands are accessible easily and there is widespread acceptance of fine-needle aspiration cytology (FNAC) in the preoperative diagnosis of salivary gland lesions [5]. The risk of complications is less with FNAC and it is simple, rapid, and inexpensive [6].

Fine needle aspiration cytology (FNAC) is being increasingly used in the diagnosis of salivary gland lesions as it is an accepted sensitive and specific technique in diagnosis of both neoplastic and non-neoplastic lesions. Fine needle aspiration cytology (FNAC) is accurate, reliable, minimally invasive, well tolerated and harmless for the patient. This technique assumes greater importance considering the lack of characteristic clinical or radiologic features that may suggest a particular diagnosis. The overall accuracy in literature has been given as sensitivity from 62 to $97.6 \%$ and specificity from 94.3 to $100 \%$. Although salivary gland tumours are rare and they account for 2-6.5\% of all the head and neck tumours, their superficial location, easy accessibility and high diagnostic accuracy makes FNAC a popular method for evaluating them. The traditional open biopsy is no longer justified because of risk of tumours spillage, bleeding, inflammation and damage to facial nerve; whereas complications of FNAC is almost negligible. The purpose of this study is to evaluate and to check the diagnostic accuracy, sensitivity and specificity of fine needle aspiration cytology in the diagnosis of salivary gland lesions.

\section{MATERIALS AND METHODS}

In this prospective study conducted in kamineni institute of Medical Sciences from October 2015 - September 2017, total cases received in the department of pathology is 85 . Among them 60 aspirations are neoplastic and patients underwent surgery and were followed by histopathological diagnosis. These 60 cases were considered for cytological and histopathological correlation of salivary gland neoplasms and calculating their diagnostic accuracy.

An informed consent was taken before performing the FNAC. FNAC was done using a 22 to 25 -gauge needle attached to a $10 \mathrm{~mL}$ disposable syringe for each prick and for each patient. No local anesthetic was used, and the needle was inserted into the lesions, either once or twice depending upon the size of the lesion. Aspirated material was used to make wet and dry smears. Four to five slides were prepared for each patient. The wet smears were fixed with Carnoy's solution for Hematoxylin and Eosin (H\&E) and with $95 \%$ alcohol for Papanicolaou stains. While air dried smears were stained with Romanowsky stain like Leishman's stain. Special stains like PAS was used whenever required. FNAC slides were analyzed and classified into unclassified, benign, suspicious for malignancy and malignant. Histopathological correlation of the available biopsies from the FNAC study was done. The biopsy specimens were fixed in $10 \%$ formalin for 24 hours and sections were stained by H\&E. SPSS 17 was used for statistical analysis for the study namely sensitivity, specificity, positive predictive value, negative predictive value and other statistical methods.

FNAC of salivary lipomatosis (10X, H\&E) showing fat globules admixed with salivary acini

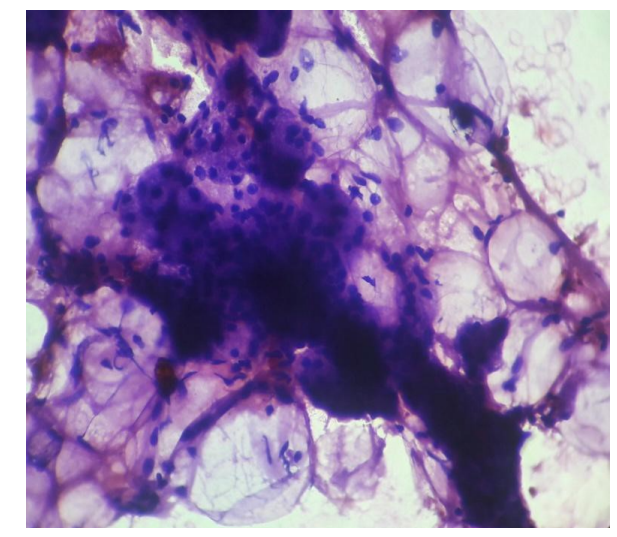


Salivary lipomatosis (10X, H\&E) - HPE showing lobules of mature adipose tissue admixed with normal salivary gland elements

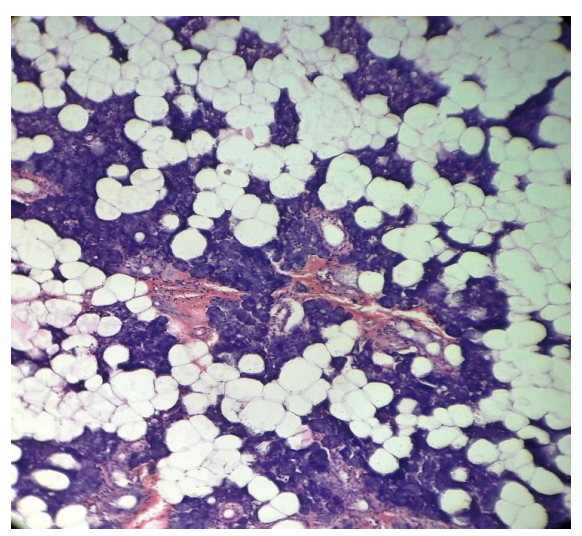

Salivary duct carcinoma (10X, H\&E) Microscopy showing intraductal component with areas of comedo type necrosis.

\section{RESULTS}

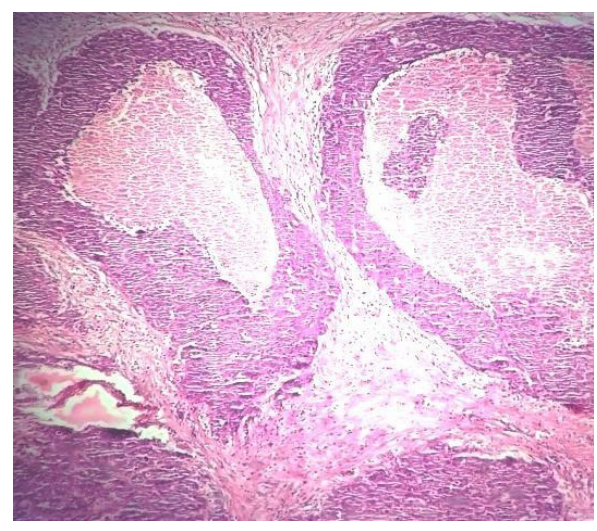

Table 1: Cytodiagnosis of benign salivary gland neoplasms $(n=57)$.

\begin{tabular}{|c|c|c|c|c|c|}
\hline Cytodiagnosis & $\begin{array}{c}\text { Parotid gland } \mathbf{n} \\
(\%)\end{array}$ & $\begin{array}{c}\text { Submandibular } \\
\text { gland } \mathbf{n}(\%)\end{array}$ & $\begin{array}{c}\text { Sublingual } \\
\text { gland } \mathbf{n}(\%)\end{array}$ & $\begin{array}{c}\text { Minor salivary } \\
\text { gland } \mathbf{~ ( \% ) ~}\end{array}$ & Total n (\%) \\
\hline Pleomorphic Adenoma & $38(66.66)$ & $11(19.29)$ & -- & $4(7.01)$ & $53(92.98)$ \\
\hline Benign cystic lesion & $2(3.50)$ & -- & -- & -- & $2(3.50)$ \\
\hline Benign spindle cell lesion & $1(1.75)$ & - & -- & -- & $1(1.75)$ \\
\hline Salivary lipomatosis & $1(1.75)$ & -- & -- & -- & $1(1.75)$ \\
\hline Total & $42(73.68)$ & $11(19.29)$ & -- & $4(7.01)$ & $57(100)$ \\
\hline
\end{tabular}

\begin{tabular}{|c|c|c|c|c|c|}
\hline Cytodiagnosis & $\begin{array}{c}\text { Parotid gland } \\
\mathbf{n}(\%)\end{array}$ & $\begin{array}{c}\text { Submandibular } \\
\text { gland n (\%) }\end{array}$ & $\begin{array}{c}\text { Sublingual } \\
\text { gland n (\%) }\end{array}$ & $\begin{array}{c}\text { Minor salivary } \\
\text { gland n (\%) }\end{array}$ & Total n (\%) \\
\hline Adenoid cystic Ca & $1(33.33)$ & -- & -- & -- & $1(33.33)$ \\
\hline MucoEpidermoid Ca & $1(33.33)$ & -- & -- & -- & $1(33.33)$ \\
\hline Salivary duct Ca & -- & $1(33.33)$ & -- & -- & $1(33.33)$ \\
\hline Total & $2(66.66$ & $1(33.33)$ & -- & -- & $3(100)$ \\
\hline
\end{tabular}

Table 3: Correlation of cytological \& histopathological diagnosis of salivary gland neoplasms $(n=60)$.

\begin{tabular}{|c|c|c|c|c|c|c|c|c|c|}
\hline \multicolumn{10}{|c|}{ Histopathological Diagnosis } \\
\hline FNAC Diagnosis & $\begin{array}{l}\text { Intraparotid } \\
\text { schwannoma }\end{array}$ & $\begin{array}{c}\text { Salivary } \\
\text { lipomatosis }\end{array}$ & $\begin{array}{l}\text { Pleomorphic } \\
\text { Adenoma }\end{array}$ & $\begin{array}{l}\text { Basal Cell } \\
\text { Adenoma }\end{array}$ & $\begin{array}{c}\text { Warthin's } \\
\text { Tumor }\end{array}$ & $\begin{array}{c}\text { Salivary duct } \\
\text { carcinoma }\end{array}$ & $\begin{array}{c}\text { Muco } \\
\text { Epidermoid } \\
\text { Carcinoma }\end{array}$ & $\begin{array}{c}\text { Adenoid } \\
\text { Cystic } \\
\text { Carcinoma }\end{array}$ & Total \\
\hline Benign Cystic lesion (2) & - & - & - & - & 1 & - & 1 & - & 2 \\
\hline Benign Spindle cell lesion (1) & 1 & - & - & - & - & - & - & - & 1 \\
\hline Salivary lipomatosis (1) & - & 1 & - & - & - & - & - & - & 1 \\
\hline Pleomorphic Adenoma (53) & - & - & 46 & 4 & - & - & 2 & 1 & 53 \\
\hline Warthin`s Tumor (0) & - & - & - & - & - & - & - & - & - \\
\hline Basal Cell Adenoma (0) & - & - & - & - & - & - & - & - & - \\
\hline Salivary duct carcinoma (1) & - & - & - & - & - & 1 & - & - & 1 \\
\hline MucoEpidermoid Carcinoma (1) & - & - & - & - & - & - & 1 & - & 1 \\
\hline Adenoid Cystic Carcinoma (1) & - & - & - & - & - & - & - & 1 & 1 \\
\hline Total & 1 & 1 & 46 & 4 & 1 & 1 & 4 & 2 & 60 \\
\hline
\end{tabular}

Table 4: The diagnostic accuracy of salivary gland neoplasms $(n=60)$.

\begin{tabular}{|c|c|c|c|}
\hline \multirow{2}{*}{ Fnac Diagnosis } & \multicolumn{3}{|c|}{ Histopathological Diagnosis } \\
\cline { 2 - 4 } & $\begin{array}{c}\text { Positive for } \\
\text { neoplasm }\end{array}$ & $\begin{array}{c}\text { Negative for } \\
\text { neoplasm }\end{array}$ & TOTAL \\
\hline Positive for neoplasm & $\mathrm{TP}=5$ & $\mathrm{FP}=0$ & $\mathbf{5}$ \\
\hline Negative for neoplasm & $\mathrm{TN}=2$ & $\mathrm{FN}=53$ & 55 \\
\hline TOTAL & $\mathbf{7}$ & $\mathbf{5 3}$ & 60 \\
\hline
\end{tabular}




\section{DISCUSSION}

During this period 85 FNAC's was performed on patients with salivary gland lesions. Among 85 aspirations, only 60 patients with neoplasms underwent surgery and are followed by histopathological diagnosis. For these 60 cases cyto-histopathological correlation is done for calculating sensitivity, specificity, and diagnostic accuracy.

In the present study age group of the patients ranged from 14-70 years. Salivary gland neoplasms were more common in the age group of 21-50 years constituting 43 cases (71.66\%). Benign neoplasms are common in 21-50 years constituting 38 cases (63.33\%). Malignant neoplasms were common in the age group of 31-40 years constituting $3(42.85 \%)$. Female distribution is $38(63.33 \%)$ and male distribution is 22 (36.66\%).

In the present study among the malignant neoplasms of salivary Glands, 1 case of Adenoid cystic carcinoma (33.33\%) is seen in the Parotid gland. One case of Mucoepidermoid carcinoma is seen in the parotid gland (33.33\%). One case of salivary duct carcinoma is seen in the Submandibular gland (33.33\%). Overall contributing to $11.66 \%$ of all neoplasms. The salivary gland lesions are more common in the major salivary glands compared to the minor salivary glands. In the major salivary glands, Parotid gland is the most common site followed by Submandibular gland. And Benign lesions were more common than the malignant lesions.

The Pleomorphic adenoma was the common benign tumor accounting for $76.66 \%$ of all tumors and $86.79 \%$ of all benign tumors. The salivary gland neoplasms were more common in the right side compared to the left side and more common in the right parotid gland $30(50 \%)$ compared to the left parotid gland $14(23.33 \%)$. These salivary gland neoplasms are classified into two diagnostic classes as, Benign lesions 53 (88.33\%) and Malignant lesions 7 (11.66\%). In the present study among the Benign neoplastic lesions, Pleomorphic adenoma was the most common lesion comprising of 53 cases (92.98\%) which is seen most common in the Parotid gland.
Two cases of Benign cystic lesions were seen in the parotid gland. One case of benign spindle cell lesion was seen in the Parotid gland. One case of salivary lipomatosis was seen in the Parotid gland.

Pleomorphic Adenoma: Cytologically 53 cases were diagnosed as pleomorphic adenoma, Histopathologically 46 cases are diagnosed as pleomorphic adenoma. In the present study, Pleomorphic adenoma is the most common benign tumor encountered. The tumors were irregular and lobulated with bosselated surface. Cut section showed grey-white, homogenous, solid areas with focal blue translucent areas in some tumors. Microscopy showed epithelial and myoepithelial cells arranged in various patterns. Few cases showed chondromyxoid areas. Few cases showed cystic change. Few cases showed squamous metaplasia with epithelial pearl formation. Similar observations were made by studies done by Evans and Cruickshank [7], Viguer JM et al [8] and Paul et al [9].

Basal Cell Adenoma: 4 cases are diagnosed on histology. Grossly the tumor showed irregular, grey white nodular mass. Microscopy showed tumor composed of uniform, small, round to oval basaloid cells. Brachtel EF stated that although fine-needle aspiration biopsy is a highly accurate tool for the diagnosis of pleomorphic adenomas, even this common salivary gland neoplasm can be diagnostically challenging and cause pitfalls in cytodiagnosis. In particular, the presence of either cystic degeneration or squamous and mucinous metaplasia can lead to a false positive diagnosis of malignancy [10].

With centrally placed nuclei and scant basophilic cytoplasm arranged in trabeculae, cords and sheets separated by fibrovascular stroma. Peripheral nuclear palisading is seen in some areas. Similar observations were made by studies done by Evans et al [7], Dong et al [11]. These 4 cases of Basal cell adenoma are falsely diagnosed as pleomorphic adenoma on cytology. Cytologically, the distinction between pleomorphic adenoma and BCA is difficult due to overlapping morphological features and sometimes because of inadequate sampling of tissue. Cellular pleomorphic adenomas with a predominance of basaloid epithelial cells can 
be difficult to distinguish from other basaloid tumors because the characteristic fibrillar matrix material is sparse. FNAC can be reliable and specific diagnosis is often possible but it is advised to perform tissue biopsy for histological examination for confirmation of diagnosis, as done in our cases.

Warthins Tumor: One case of warthins tumor was falsely diagnosed as benign cystic lesion as the smears showed mainly fluid and benign acinar cells even on repeated aspiration. On histology it turned out to be WT with predominant cystic change. Histologically, WT characteristically consists of cystic and solid areas. The cystic area is lined by layers of tall columnar oncocytic luminal cells and flattened or cuboidal basal cells, while the stroma consists of lymphocytes. The cytological diagnosis of cystic salivary gland lesions is rather difficult due to the wide range of lesions that enter the differential diagnosis which include chronic sialadenitis, WT, acinic cell carcinoma, pleomorphic adenoma and mucoepidermoid carcinoma $[13,14]$.

Salivary Lipomatosis: In the present study one case of salivary lipomatosis on FNAC is encountered which correlated well with the histopathology. Histology showed lobules of mature adipose tissue admixed with normal salivary gland elements. The term sialolipoma was coined by Nagao et al for biphasic salivary gland tumors. Fat-containing salivary gland tumors and lesions are heterogeneous in their histogenesis and morphological appearances with great overlap between some lesions. They encompass well defined salivary gland tumor entities (pleomorphic adenoma and myoepithelioma with lipometaplasia), tumors with oncocytic and lipomatous components (oncocytic lipoadenoma), tumors that recapitulate the architecture of normal parotid tissue (sialolipoma), true adipocytic neoplasms indistinguishable from cutaneous and soft tissue fatty tumors (lipoma and liposarcoma and their variants) and miscellaneous functional, metabolic or atrophic changes (lipomatosis, lobular atrophy). Careful analysis of both the overall architecture and the cellular constituents of a given lesion are mandatory for appropriate classification of these uncommon conditions [15].
Intraparotid Schwannoma: On FNAC - Lesion composed of fragments of spindle cells without nuclear pleomorphism, or mitoses and a diagnosis of benign spindle cell lesion is given Grossly, schwannoma was round, encapsulated, pink to tan mass with distinct borders. On microscopy, the tumor is a well-encapsulated mass lesion with pushing borders, without invasion of the surrounding tissue. There are areas of relative hypocellularity with abundant acellular material, as well as areas of hypercellularity with oval to elongated hyperchromatic nuclei, inconspicuous nucleolus, and fibrillary eosinophilic cytoplasm and occasional Verocay body formation. Possibility of intraparotid schwannoma should be considered under differentials and the imaging modalities especially MRI revealing characteristic "string sign" further confirm the diagnosis [16].

Mucoepidermoid Carcinoma: In the present study FNAC of one case of Mucoepidermoid carcinoma correlated well with histopathology [17]. Gross features show a round to oval mass with cut surface showing grey white to grey brown areas with cystic space containing mucinous fluid. Microscopic features showed cystic spaces lined by mucous cells, intermediate cells and squamous cells in varied proportions. Cystic spaces are filled with mucin. 1 case of low grade mucoepidermoid carcinoma was falsely diagnosed as benign cystic lesions cytologically. The reason for false negative diagnosis as benign cystic lesion is scant cellularity and aspiration of only cystic contents. Abundant quantities of hypo cellular mucus can be aspirated from low grade mucoepidermoid carcinoma which can lead to false negative diagnosis of benign cystic disease or warthins tumor.

Adenoid Cystic Carcinoma: FNAC of One case of adenoid cystic carcinoma correlated well with histopathology. Gross features showed a round to oval mass. Cut section is grey white to grey brown. Microscopic features showed tumor cells arranged in cribriform pattern, solid groups, cords and trabecular pattern. The tumor is composed of basaloid cells. The tumor cells are small, round to oval with scant eosinophilic cytoplasm and hyperchromatic nucleus. Cystic changes were seen. Mucinous material is noted in cystic spaces and there is intervening fibro 
collagenous stroma. Similar observations were made by studies done by Evans et al [7], Dong et al [11]. There was perineural invasion in one case. One case was falsely diagnosed as pleomorphic adenoma on cytology. Jesse Jaso et al states that the differential diagnosis of ACC includes tumors that also exhibit tubular and cribriform structures such as polymorphous lowgrade adenocarcinoma, tumors with basaloid cellular morphology such as basal cell adenoma and basal cell adenocarcinoma, and tumors with a dual population of ductal and myoepithelial cells such as pleomorphic adenoma [18].

$\mathrm{PA}$ is perhaps the most common problem in the differential diagnosis of ACC, because both PA and ACC can grow in a cylindromatous or cribriform pattern, complete with hyaline globule formation.

Careful identification of plasmacytoid myoepithelial cells is the most helpful cytomorphologic feature for distinguishing PA from parotid malignancies, especially ACC. Also, in the benign tumors, the cells interdigitate intricately with the fibrillary connective tissue associated with them. This is in contrast to the sharp interface between tumor cells and extracellular matrix material that forms the spheres and cylinders of ACC. Lowhagen et al advocate that if the cribriform structures appear together with any features of PA, these last findings should be emphasized and a diagnosis of PA should be rendered [19].

Salivary Duct Carcinoma: Histologically one case of salivary duct carcinoma is diagnosed, which is cytologically concordant. Cytologically cells are polygonal with oncocytic appearance and large areas of necrosis with few cribriform groups. Gross examination shows tumor is white-tan mass, firm with focal cystic component. An infiltration of the adjacent parenchyma is obvious. Microscopically tumor is composed of an intraductal and invasive components. Intraductal component is predominantly solid with comedo-like central necrosis. The infiltrative component is made of glands, cords of cells with desmoplastic reaction. Cells have eosinophilic cytoplasm, marked nuclear pleomorphism, vesicular nuclei and prominent nucleoli. Perkins Mukunyadzi et al stated that initial recognition of salivary duct carcinoma as a high grade neoplasm is crucial as this tumor carries a dismal prognosis [20].

Among 85 aspirations, 60 patients with neoplasms of salivary glands underwent surgery, followed by histopathological diagnosis for which cytohisto correlation was done. Hence the sensitivity of present study is $71.4 \%$, specificity is $100 \%$ and diagnostic accuracy is $96.6 \%$ which is almost comparable with the studies done by O Dwyer [21] and Bandar S [22] and Naeem sultan Ali et al [23]. In the present study correlation value is 0.631 and $P$ value is 0.00 which is statistically significant similar to studies done by Gupta R [24], Shetty A [25], Faizal B [26]. the present study reaffirms that FNAC of the salivary glands neoplasms, being a quick, safe, and affordable procedure offers an invaluable and highly accurate initial diagnostic approach for the management of patients.

\section{CONCLUSION}

An accurate cytologic diagnosis can avoid unwarranted surgery. Familiarity with the cytological features of rare lesions and morphological variations of the commoner lesions is necessary to avoid misinterpretation. Cystic lesions remain a problematic area for correct diagnosis on cytology with high diagnostic sensitivity, specificity, accuracy present study reaffirms that FNAC of the salivary glands neoplasms, being a quick, safe, and affordable procedure offers an invaluable and highly accurate initial diagnostic approach for the management of patients, whether it is local excision for a benign neoplasm, radical surgery for a malignant neoplasm or alternate treatment. However, there still remain few cases that may be inaccurately diagnosed on cytology due to overlapping features and in these cases histopathology is the only modality for final diagnosis.

\section{REFERENCES}

[1]. Christopher D M Fletcher. Diagnostic histopathology of tumors. 2nd Edition Vol. 1. Churchill Livingstone Publications 2000;239:316.

[2]. Jennifer A Young. Fine needle Aspiration Cytology: Blackwell Scientific Publications; 1993.

[3]. Das D, Saha S, Satyanarayana V. Histopathologic spectrum of salivary gland neoplasms. International $\mathrm{J}$ of Healthcare and Biomedical Research. 2016;4(2):48-55. 
[4]. Fernandes GC, Pandit AA. Diagnosis of salivary gland tumors by FNAC. Bombay hospital Journal. 2007;42 (1).

[5]. Rolf J. Postema, Mari-Louise F. van Velthuysen. Accuracy of fine needle aspiration cytology of salivary gland lesions in the Netherlands cancer institute, Wiley Inter Science, 2004may:418-24.

[6]. Peter Zbaren, Michel Nuyens, Heinz Loosli, Stauffer. Diagnostic Accuracy of fine needle aspiration cytology and frozen section in primary parotid carcinoma. Cancer 2004; 9 (100):1876-81.

[7]. Evans RW and Cruickshank AH. Epithelial tumors of the salivary glands. Vol.1.Philadelphia: WB Saunders Co., 1970.

[8]. Viguer JM, Vicandi B, Heffernan JA, et al. Fine needle aspiration cytology of pleomorphic adenoma-An analysis of 212 cases. Acta cytol 1997;41:786-94.

[9]. Paul J. Salivary Gland Tumors- a 5 year study. 1996 : 1-156.

[10]. Brachtel EF, Pilch BZ, Khettry U, Zembowicz A, Faquin WC. Fine needle aspiration biopsy of a cystic pleomorphic adenoma with extensive adnexa-like differentiation: differential diagnostic pitfall with mucoepidermoid carcinoma. Diagn Cytopathol. 2003 Feb; 28(2):100-3

[11]. Dong KL, Kye WC, Chung HB, Han SJ, Young HK, Young IS. Basal cell adenoma of the parotid gland: characteristics of 2 phase helical computed tomography and magnetic resonance imaging. J Comput Assist Tomogr 2005; 29: 884-8.

[12]. Ellis GL., Auclair PL., Gnepp DR., Goode RK. Other malignant epithelial neoplasms. Chapter 27 : Surgical pathology of the salivary glands. Eds: Ellis GL., Auclair PL., Gnepp RD. Vol. 25. Philadelphia: WB Saunders Co. 1991:455 - 88.

[13]. Sangeetha N, Karthika V, Latha S. Cytological analysis of salivary gland lesions with histopathological correlation.IJPBS.2013;3(4):122-8.

[14]. Ameli F, Baharoom A, Nurismah ,Akmal S N . Diagnostic challenges in fine needle aspiration cytology of salivary gland lesions. Malaysian J Pathol 2015; 37(1) :11 - 8 .

[15]. Agaimy A. Fat-Containing Salivary Gland Tumors: A Review. Head and Neck Pathology. 2013;7:90-6.

[16]. Jain R, Gupta R, Kudesia M, Singh S. Fine needle aspiration cytology in diagnosis of salivary gland lesions: A study with histologic comparison. CytoJournal. 2013;10:5
[17]. Pires, Fabio R.Almeida D. Oslei P, Araujo D.Vera C et al. Prognostic factors in head and neck mucoepidermoid carcinoma. Archives of Otolaryngologyhead and neck surgery 2004;130(2): 849-56.

[18]. Jesse Jaso, Reenu Malhotra, Adenoid Cystic Carcinoma. Archives of Pathology \& Laboratory Medicine:2011;135:511-5.

[19]. Gahine R, Sudarshan V, Hussain N. Krishnani C. Plemorphic adenoma: A diagnostic pitfall in the diagnosis of salivary gland lesions on FNAC: Case reports with review of the literature. CytoJournal 2010:7:17

[20]. Perkins Mukunyadzi, Ricardo H. Bardales .Tissue effects of salivary gland fine-needle aspiration does this procedure preclude accurate histologic diagnosis. Am J Clin Pathol 2000;114:741-5.

[21]. O Dwyer P, Farr WB, James AG. Needle aspiration of major salivary glands. Its value. Cancer 1986;57:554-7.

[22]. Bandar S, Priyadarshini KVN, Avanigadda I, et al. Cytohistological study of salivary gland lesions. J.

ve Evolution Med. Dent. Sci. 2016;5(103):7571-6.

[23]. Naeem Sultan Ali, Shabbir Akhtar. Diagnostic accuracy of fine needle aspiration cytology in parotid Lesions. International Scholarly Research Network ISRN Surgery. 2011;2011:5.

[24]. Gupta R, Dewan D, Kumar D, Suri J. Fine needle aspiration cytology (FNAC) of salivary gland lesions with histopathological correlation in a district hospital of Jammu region. Indian J Pathol Oncol. 2016;3:327.

[25]. Shetty A, Geethamani V. Role of fine-needle aspiration cytology in the diagnosis of major salivary gland tumors: A study with histological and clinical correlation. Journal of Oral and Maxillofacial Pathology/ : JOMFP. 2016;20(2):224-9.

[26]. Faizal B, Bhate JJ, Hiran KR. Reliability of Fine Needle Aspiration Cytology in salivary neoplasms: surgeon $s$ perspective. Amrita Journal of Medicine. 2014;10(2):23- 9.

How to cite this article:

Gouthami S, Sunitha Gattigorla, Sheshagiri T. CYTOMORPHOLOGY AND CORRELATION WITH THE HISTOPATHOLOGICAL DIAGNOSIS OF SALIVARY GLAND NEOPLASMS. Int J Intg Med Sci 2018;5(9):752-758. DOI: $10.16965 /$ ijims.2018.137 